\title{
SOLUSI KUADRAT TERKECIL MODEL REGRESI FUZZY DENGAN VARIABEL DEPENDEN FUZZY SIMETRIS
}

\author{
Iqbal Kharisudin \\ Jurusan Matematika FMIPA Universitas Negeri Semarang \\ Email: iqbal_kh@staff.unnes.ac.id
}

\begin{abstract}
ABSTRAK
Diketahui bahwa model regresi biasa digunakan untuk menganalisis data-data tegas. Pada kondisi terdapat ketidakpastian (ketidaktepatan, ketidakjelasan) nilai-nilai variabel terobservasi, maka model regresi fuzzy diperlukan. Pada makalah ini dibahas suatu model regresi fuzzy dengan variabel dependen fuzzy simetris dan variabel independen tegas menggunakan pendekatan kuadrat terkecil. Metode yang digunakan untuk menemukan model linear adalah meminimalkan fungsi jarak fuzzy antara variabel terobservasi dengan estimasi variabel dependen atau nilai teoritis yang berkorespondensi. Ditunjukkan bahwa solusi dari model ini merupakan generalisasi model regresi klasik. Selanjutnya dibahas sifat-sifat berkaitan dengan solusi model yang diperoleh.
\end{abstract}

Kata kunci: model pusat, model tepi, jarak fuzzy, solusi iteratif.

\section{ABSTRACT}

It is known that the regression model used to analyze the crisp data. In the condition that there is uncertainty (imprecision, vagueness) on values of observed variables, then the fuzzy regression model is required. In this paper discussed a fuzzy regression model with symmetrical fuzzy dependent variable and crisp independent variables using the least squares approach. The method used to find the linear model is to minimize the distance function between observed fuzzy variables with the estimation dependent variable or the corresponding theoretical value. It is shown that the solution of this model is a generalization of the classical regression model. Further discussion is about the properties of solution of the model.

Keyword: center model, spread model, fuzzy distance, iterative solution.

\section{PENDAHULUAN}

Penalaran statistik (statistical reasoning) dipengaruhi oleh beberapa jenis sumber ketidakpastian, seperti: keacakan (randomness), ketidaktepatan (imprecision), ketidakjelasan (vagueness), ketidaktahuan sebagian (partial ignorance), dan sebagainya. Dalam konteks analisis regresi, terdapat beberapa aspek ketidakpastian yang sering diperhatikan, yaitu ketidakpastian berkaitan dengan: (1) hubungan antara variabel dependen dengan variabel independen, (2) hubungan antara data terobservasi dengan "semesta" data yang mungkin, dan (3) ketidakpastian (ketidaktepatan, ketidakjelasan) nilai-nilai variabel terobservasi (Coppi, 2008).

Dalam paradigma statistik tradisional, ketidakpastian (1) dan (2) telah banyak ditangani dengan sangat memuaskan. Untuk menjawab permasalahan ketidakpastian (3), telah banyak para peneliti yang mencoba mengusulkan berbagai metode sebagai alternatif. Seiring dengan perkembangan penelitian, pada dekade terakhir, telah banyak penelitian yang berupaya mengembangkan koalisi antara teori himpunan fuzzy dan teori 
statistik. Tujuan yang hendak dicapai di antaranya adalah untuk: (1) memperkenalkan permasalahan analisis data baru berkaitan dengan relasional fuzzy, (2) membangun model formal yang menggabungkan randomness dengan fuzziness, (3) mengembangkan metodologi statistik univariate dan multivariate dalam menangani data bernilai fuzzy, dan (4) menyertakan konsep fuzzy dalam membantu menyelesaikan permasalahan statistik tradisional dengan data non-fuzzy (Coppi dkk., 2006).

Secara umum terdapat dua pendekatan yang berbeda dalam analisis regresi fuzzy. Pertama pendekatan berbasis konsep possibilistic yang pertama kali diperkenalkan oleh Tanaka dkk. (1982). Kedua adalah pendekatan berbasis kuadrat terkecil, yaitu perluasan metode kuadrat terkecil dalam setting fuzzy. Kedua pendekatan ini mempunyai perbedaan dalam metode optimasi fungsional untuk membangun model regresi "terbaik".

Salah satu pendekatan kuadrat terkecil dalam analsis regresi fuzzy diusulkan oleh D'Urso dkk. Metode yang digunakan untuk menemukan model linear adalah meminimalkan fungsi jarak fuzzy antara variabel terobservasi dan variabel output yang didefinisikan dalam suatu ruang metrik tertentu. Tulisan yang membahas masalah ini di antaranya D'Urso dan Gastaldi 2000, 2002, Coppi dan D'Urso 2003, D'Urso 2003, D'Urso dan Giordani 2003, D'Urso dan Giordani 2006, Coppi dkk. 2006, D'Urso dan Santoro 2006a, 2006b. Dalam tulisan ini dikaji model regresi dengan variabel dependen fuzzy simetris dan variabel independen tegas. Selanjutnya dibahas bentuk solusi model dengan pendekatan kuadrat terkecil dan beberapa bukti sifat-sifat dari solusi model.

\section{KONSEP FUZZY UNTUK ANALISIS REGRESI}

Untuk merepresentasikan ketidakpastian dalam permasalahan kehidupan diperlukan konsep fuzzy yang diperkenalkan oleh L. A. Zadeh pada 1965 dan dengan konsep bilangan fuzzy (Zimmermann, 1991; Taheri, 2008). Pada dasarnya kita semua sering menggunakan konsep fuzzy, aturan samar, dan ketidaktepatan informasi untuk mengambil keputusan dalam situasi yang tidak menentu. Oleh karena itu model-model komputasional dari sistem real perlu juga bisa mengenali, merepresentasikan, memanipulasi, menginterpretasikan, dan menggunakan ketidakpastian (Bezdek (1993) dalam Coppi dkk., 2006). Kelas umum dari data fuzzy dinyatakan dengan (selanjutnya disebut dengan) data fuzzy LR. Data fuzzy LR dapat dinyatakan dengan matriks data fuzzy (Coppi, 2006).

\section{Himpunan dan Bilangan Fuzzy}

Teori himpunan tegas didasarkan pada logika dwi nilai (two-valued logic) sebagai fungsi karakteristik yang memetakan setiap elemen hanya pada dua nilai yaitu 0 dan 1 . Teori himpunan fuzzy didasarkan pada logika multi nilai (multi-valued logic) sehingga fungsi karakteristiknya memetakan nilai-nilai kedalam suatu range tertentu yang menunjukkan derajat keanggotaan setiap anggota. Dalam konteks ini, 
fungsi karakteristik disebut dengan fungsi keanggotaan (membership function) dan range adalah interval $[0,1]$. Fungsi keanggotaan memetakan setiap anggota himpunan fuzzy ke dalam derajat keanggotaan dari 0 sampai dengan 1, yaitu:

$$
\mu_{\tilde{A}}: \Omega \rightarrow[0,1] .
$$

Himpunan fuzzy $\tilde{A}$ dalam $\Omega$ dapat dinyatakan sebagai pasangan terurut dari sebarang elemen $x$ dan nilai keanggotaannya, yaitu:

$$
\tilde{A}=\left\{\left(x, \mu_{\tilde{A}}(x)\right) \mid x \in \Omega\right\} .
$$

Untuk suatu $x_{0} \in \Omega$, nilai $\mu_{\tilde{A}}\left(x_{0}\right)$ menyatakan derajat keanggotaan $x_{0}$ di dalam $\tilde{A}$. Semakin besar nilai $\mu_{\tilde{A}}\left(x_{0}\right)$, maka semakin tinggi derajat keanggotaan $x_{0}$ di dalam $\tilde{A}$. Jika fungsi keanggotaan hanya menggunakan nilai 0 dan 1 , maka himpunan fuzzy menjadi himpunan tegas (crisp set) sehingga himpunan fuzzy merupakan generalisasi dari himpunan tegas. Derajat keanggotaan merupakan ukuran subjektif yang bergantung pada perbedaan individu dalam merepresentasikan konsep yang abstrak. Konsep yang sama bisa jadi diinterpretasikan dengan cara yang berbeda bergantung pada konteksnya.

Bilangan fuzzy didefinisikan berdasarkan konsep himpunan fuzzy. Bilangan fuzzy dapat didefinisikan secara umum dengan menggunakan konsep himpunan fuzzy normal dan konveks maupun secara khusus dengan menggunakan fungsi keanggotaan.

Definisi 1.1.1. (Chen dan Pham, 2001). Himpunan fuzzy $\tilde{A}$ di dalam $\Omega$ dikatakan konveks jika dan hanya jika setiap $\tilde{A}_{\alpha}$ untuk $\alpha \in(0,1]$ adalah konveks, yaitu untuk setiap $x_{1}, x_{2} \in \tilde{A}$ dan $\beta \in[0,1]$, berlaku $\mu_{\tilde{A}}\left(\beta x_{1}+(1-\beta) x_{2}\right) \geq \min \left\{\mu_{\tilde{A}}\left(x_{1}\right), \mu_{\tilde{A}}\left(x_{2}\right)\right\}$. Catatan 1.1.2. Jika $\Omega=\mathfrak{R}$ himpunan bilangan real, dan fungsi keanggotaan himpunan fuzzy adalah kontinu, maka himpunan level- $\alpha, \tilde{A}_{\alpha}$, dari himpunan fuzzy konveks adalah interval tertutup.

Definisi 1.1.3. (Taheri, 2008, Giachetti dan Young, 1997). Bilangan fuzzy $\tilde{X}$ adalah himpunan fuzzy normal dan konveks pada garis real $\mathfrak{R}$ yang memenuhi (i) terdapat tepat satu $x_{0} \in \mathfrak{R}$ dengan $\mu_{\tilde{X}}\left(x_{0}\right)=1$ dan (ii) $\mu_{\tilde{X}}$ bersifat upper semi-continuous.

Bentuk khusus dari representasi bilangan fuzzy yang dapat meningkatkan efisiensi komputasional adalah bilangan fuzzy tipe LR. Bilangan fuzzy tipe LR paling banyak dan mudah digunakan untuk mendeskripsikan data.

Definisi 1.1.4. (Zimmermann, 1991). Misalkan L (dan R) adalah fungsi berbentuk turun dari $\mathfrak{R}^{+}$ke $[0,1]$ dengan $L(0)=1 ; L(x)<1$ untuk setiap $x>0 ; L(x)>0$ untuk setiap $x<1$; $L(1)=0$ atau $(L(x)>0$ untuk setiap $x$ dan $L(+\infty)=0) . \tilde{X}$ disebut bilangan fuzzy $L R_{1}$ jika untuk $m, \alpha>0, \beta>0$ dalam $\mathfrak{R}$, fungsi keanggotaan $\tilde{X}$ didefinisikan

$$
\mu_{\tilde{X}}(x)= \begin{cases}L\left(\frac{m-x}{\alpha}\right), & \text { untuk } x<m, \\ R\left(\frac{x-m}{\beta}\right), & \text { untuk } x \geq m,\end{cases}
$$

dengan $m$ disebut nilai mean dari $\tilde{X}$ dan $\alpha$ dan $\beta$ masing-masing disebut tepi kiri dan tepi 
kanan. Bilangan fuzzy $\tilde{X}$ dinyatakan dengan $\tilde{X}=(m, \alpha, \beta)_{L R}$.

\section{Jarak dan Ruang Metrik Fuzzy}

Pada bagian ini dikemukakan definisi jarak antara dua bilangan fuzzy simetris dan sifat ruang metrik berdasarkan definisi jarak tersebut. Misalkan $\mathcal{S}_{L L}(\mathfrak{R})$ menyatakan himpunan semua bilangan fuzzy simetris.

Definisi 1.2.1. (Yang dan Ko, 1996). Misalkan $\tilde{X}=\left(m_{x}, \alpha_{x}, \beta_{x}\right)_{L R} \quad$ dan $\quad \tilde{Y}=\left(m_{y}, \alpha_{y}, \beta_{y}\right)_{L R}$ adalah bilangan fuzzy $L R$ di dalam $\mathcal{S}_{L L}(\Re)$. Jarak antara dua bilangan fuzzy $\tilde{X}$ dan $\tilde{Y}$ didefinisikan dengan

$$
\begin{aligned}
d_{L R}^{2}(\tilde{X}, \tilde{Y})=( & \left.m_{x}-m_{y}\right)^{2} \\
& +\left[\left(m_{x}-\lambda \alpha_{x}\right)-\left(m_{y}-\lambda \alpha_{y}\right)\right]^{2} \\
& +\left[\left(m_{x}+\rho \beta_{x}\right)-\left(m_{y}+\rho \beta_{y}\right)\right]^{2}
\end{aligned}
$$

dengan $\quad \lambda=\int_{0}^{1} L^{-1}(\omega) \mathrm{d} \omega \quad$ dan $\quad \rho=$ $\int_{0}^{1} R^{-1}(\omega) \mathrm{d} \omega$

Pada definisi 1.2 .1 di atas, $\lambda$ dan $\rho$ menyatakan pengaruh bentuk dari fungsi keanggotaan terhadap jarak antara dua bilangan fuzzy. Nilai $\lambda$ dan $\rho$ memiliki peran ganda, yaitu berhubungan dengan variabilitas fungsi keanggotaan dan menurunkan penekanan pada tepi, karena pada kenyataannya bobot pusat lebih besar daripada bobot tepi. Selanjutnya pada definisi 1.2.1, jika kedua bilangan adalah bilangan fuzzy simetris $\left(\alpha_{x}=\beta_{x}, \alpha_{y}=\beta_{y}\right.$, dan $\left.\lambda=\rho=\int_{0}^{1} L^{-1}(\omega) \mathrm{d} \omega\right)$, maka diperoleh jarak antara dua bilangan fuzzy simetris $\tilde{X}$ dan $\tilde{Y}$, yaitu:

$d_{L L}^{2}(\tilde{X}, \tilde{Y})=3\left(m_{x}-m_{y}\right)^{2}+2 \lambda^{2}\left(\alpha_{x}-\alpha_{y}\right)^{2}$.
Teorema 1.2.2. (Yang dan Ko, 1996). $\left(\mathcal{S}_{L L}(\Re), d_{L L}\right)$ adalah ruang metrik.

Teorema 1.2.3. (Yang dan Ko, 1996). $\left(\mathcal{S}_{L L}(\mathfrak{R}), d_{L L}\right)$ adalah ruang metrik complete.

\section{MODEL REGRESI FUZZY}

Analisis regresi linear dengan model fuzzy pertama kali diusulkan oleh Tanaka dkk. pada tahun 1982. Berdasarkan metode ini, koefisien regresi merupakan bilangan fuzzy yang dapat dinyatakan sebagai interval dengan fungsi keanggotaan. Perkembangan teori fuzzy pada analisis regresi sejak dikemukakan oleh Tanaka dkk. sangat pesat. Referensi yang cukup lengkap berkaitan dengan perkembangan metode regresi fuzzy diantaranya seperti Chang dan Ayyub (2001) dan Shapiro (2005). Pendekatan lain yang juga banyak diteliti adalah kuadrat terkecil dalam analisis regresi fuzzy. Pendekatan ini telah banyak diteliti dalam dua dekade terakhir, di antaranya oleh Celmins (1987), Diamond (1988), Chang dan Lee (1996), Ma dkk. (1997), dan Wu (2003). Penelitian-penelitian dalam konteks tersebut sangat beragam dan masih menjadi topik penelitian yang berkembang.

Ide dasar analisis regresi fuzzy yang dikembangkan adalah memodelkan pusat (center) dari variabel dependen fuzzy simetris dengan mengadopsi model regresi klasik, selanjutnya secara simultan memodelkan tepi variabel dependen fuzzy melalui regresi linear sederhana. Hubungan antara $\tilde{Y}$ (variabel dependen fuzzy simetris) dengan $X_{1}, \ldots, X_{k}$ (variabel independen tegas) dinyatakan dengan 
model (D’Urso dan Gastaldi, 2000; D’Urso dan Santoro, 2006b):

$$
\begin{gathered}
\mathbf{m}=\boldsymbol{\mu}+\boldsymbol{\varepsilon}, \\
\mathbf{m}-\mathbf{l}=\boldsymbol{\mu}-\boldsymbol{\delta}+\boldsymbol{\varepsilon}_{L} ; \\
\mathbf{m}+\mathbf{l}=\boldsymbol{\mu}+\boldsymbol{\delta}+\boldsymbol{\varepsilon}_{R} ; \\
\text { dengan } \boldsymbol{\mu}=\mathbf{X} \mathbf{a} \text { dan } \boldsymbol{\delta}=\boldsymbol{\mu} b+\mathbf{1} d,
\end{gathered}
$$

dimana 1 adalah vektor 1-an berukuran $(n \times$ $1, \mathbf{X}$ matriks berukuran $n \times k+1$ berisi vektor $\mathbf{1}$ dan variabel input $\left[\mathbf{x}_{1}, \ldots, \mathbf{x}_{k}\right] ; \mathbf{m}, \boldsymbol{\mu}$ masingmasing adalah vektor pusat terobservasi dan vektor pusat interpolasi berukuran $(n \times 1) ; \mathbf{l}, \boldsymbol{\delta}$ masing-masing adalah vektor tepi terobservasi dan vektor tepi interpolasi berukuran $(n \times 1)$; a vektor koefisien/parameter regresi untuk m berukuran $((k+1) \times 1) ; \quad b \quad$ dan $d$ koefisien/parameter regresi untuk model tepi; serta $\boldsymbol{\varepsilon}, \boldsymbol{\varepsilon}_{L}$, dan $\boldsymbol{\varepsilon}_{R}$ adalah vektor residual.

Model regresi tersebut di bangun atas tiga model linear. Pertama interpolasi pusat dari observasi fuzzy, kedua dan ketiga adalah model untuk batas bawah (pusat - tepi) dan model untuk batas atas (pusat + tepi) yang dibangun berdasarkan model pertama. Dalam kasus variabel output adalah simetris, maka tepi kiri sama dengan tepi kanan, sehingga model kedua dan model ketiga mempunyai estimasi tepi yang sama.

\section{Fungsi Objektif}

Berdasarkan kriteria kuadrat terkecil, parameter dari model (2.0.1) diestimasi dengan meminimalkan kuadrat jarak antara variabel dependen terobservasi $\tilde{Y}$ dengan nilai teoritis yang berkorespondensi $\tilde{Y}^{*}$ yang didefinisikan melalui model (2.0.1). Untuk tujuan ini, digunakan konsep jarak Euclid untuk bilangan fuzzy $L L$, yaitu:

$$
\begin{aligned}
\Delta_{L L}^{2}=\| \mathbf{m}-\boldsymbol{\mu} & \|^{2} \\
+ & \|(\mathbf{m}-\lambda \mathbf{l})-(\boldsymbol{\mu}-\lambda \boldsymbol{\delta})\|^{2} \\
+ & \|(\mathbf{m}+\lambda \mathbf{l})-(\boldsymbol{\mu}+\lambda \boldsymbol{\delta})\|^{2} \\
=3(\mathbf{m}-\boldsymbol{\mu})^{\prime} & (\mathbf{m}-\boldsymbol{\mu}) \\
& +2 \lambda^{2}(\mathbf{l}-\boldsymbol{\delta})^{\prime}(\mathbf{l}-\boldsymbol{\delta}) .
\end{aligned}
$$

Nilai parameter $\lambda$ berkaitan dengan bentuk fungsi dari jenis variabel fuzzy (lihat Kharisudin dan Subanar, 2009). Berdasarkan jenis fungsi keanggotaan bilangan fuzzy simetris, nilai $\lambda$ pada dasarnya merupakan penyesuaian tepi kiri dan tepi kanan pada saat perhitungan batas bawah dan batas atas bilangan fuzzy $\tilde{y}_{i}, \tilde{y}_{i}^{*}(i=1,2, \ldots, n)$. Pada persamaan (2.1) $\lambda$ menyatakan bobot yang berbeda antara pusat dengan tepi (kiri maupun kanan). Dalam estimasi parameter regresi, nilai $\lambda$ didefinisikan secara subjektif sesuai dengan bobot pusat dan tepi variabel fuzzy dengan memperhatikan bentuk spesifik dari fungsi keanggotaan yang memberikan karakter setiap datum fuzzy. Secara umum bobot tersebut selalu kurang dari satu, dengan alasan bahwa bobot untuk tepi selalu kurang dari bobot untuk pusat variabel fuzzy.

Berdasarkan model (2.0.1), basis jarak (2.1) dapat ditulis menjadi

$$
\begin{aligned}
\Delta_{L L}^{2}=3\left(\mathbf{m}^{\prime} \mathbf{m}\right. & \left.-2 \mathbf{m}^{\prime} \mathbf{X a}+\mathbf{a}^{\prime} \mathbf{X}^{\prime} \mathbf{X a}\right) \\
+ & 2 \lambda^{2}\left(\mathbf{l}^{\prime} \mathbf{l}-2 \mathbf{l}^{\prime} \mathbf{X} \mathbf{a} b\right. \\
& -2 \mathbf{l}^{\prime} \mathbf{1} d+\mathbf{a}^{\prime} \mathbf{X}^{\prime} \mathbf{X} \mathbf{a} b^{2} \\
+ & \left.2 \mathbf{1}^{\prime} \mathbf{X} \mathbf{a} b d+n d^{2}\right)
\end{aligned}
$$


Dengan demikian fungsi objektif kuadrat terkecil menjadi

$$
\begin{gathered}
\min _{\mathbf{a}, b, d}\left[3\left(\mathbf{m}^{\prime} \mathbf{m}-2 \mathbf{m}^{\prime} \mathbf{X a}+\mathbf{a}^{\prime} \mathbf{X}^{\prime} \mathbf{X a}\right)+\right. \\
2 \lambda 2 \mathbf{l}^{\prime} \mathbf{l}-2 \mathbf{l}^{\prime} \mathbf{X} \mathbf{a} b-2 \mathbf{l}^{\prime} \mathbf{1} d+\mathbf{a}^{\prime} \mathbf{X}^{\prime} \mathbf{X a} b 2+ \\
2 \mathbf{1}^{\prime} \mathbf{X} \mathbf{a} b d+n d 2 .
\end{gathered}
$$

\section{Solusi Kuadrat Terkecil Iteratif}

Untuk menentukan solusi masalah (2.1.1), dicari turunan parsial $\Delta_{L L}^{2}$ terhadap parameter a, $b$, dan $d$ untuk nilai sama dengan nol, sehingga diperoleh sistem persamaan sebagai berikut.

$$
\begin{aligned}
\mathbf{a}= & \left(3+2 \lambda^{2} b^{2}\right)^{-1}\left(\mathbf{X}^{\prime} \mathbf{X}\right)^{-1} \mathbf{X}^{\prime}[3 \mathbf{m}+ \\
& 2 \lambda 2 \mathbf{l} b-\mathbf{1} b d . \\
b= & \left(\mathbf{a}^{\prime} \mathbf{X}^{\prime} \mathbf{X a}\right)^{-1} \mathbf{a}^{\prime} \mathbf{X}^{\prime}(\mathbf{l}-\mathbf{1} d) . \\
d= & n^{-1} \mathbf{1}^{\prime}(\mathbf{l}-\mathbf{X} \mathbf{a} b) .
\end{aligned}
$$

Solusi iteratif dari sistem persamaan di atas diperoleh dengan mengasumsikan bahwa $\mathbf{X}$ mempunyai rank penuh. Prosedur optimisasi dengan menggunakan algoritma iteratif berdasarkan persamaan (2.2.1) - (2.2.3) tidak dijamin diperolehnya minimum global, hanya minimum lokal saja. Dengan demikian, sangat disarankan untuk menggunakan algoitma iterasi dengan beberapa nilai awal untuk mengetahui stabilitas solusi (D’Urso dan Santoro, 2006a).

Selanjutnya dapat dilihat bahwa pada kasus variabel dependen tegas (crisp) yaitu $\mathbf{l}=\mathbf{0}$ dan $b=d=0$ maka estimasi a yang termuat dalam (2.2.1) akan menghasilkan solusi kuadrat terkecil biasa yaitu $\left(\mathbf{X}^{\prime} \mathbf{X}\right)^{-1} \mathbf{X}^{\prime} \mathbf{m}$. Dengan demikian model dan solusi pada sistem persamaan di atas merupakan generalisasi dari model regresi linear klasik, jika variabel dependen memuat ketidakpastian.

\section{Sifat Solusi Kuadrat Terkecil dari Model}

Pada bagian ini akan dibuktikan sifat-sifat solusi kuadrat terkecil iteratif (2.2.1) s.d. (2.2.3) dari model (2.0.1). Berkaitan dengan model (2.0.1), selanjutnya estimasi kuadrat terkecil iteratif dari $\boldsymbol{\mu}$ dan $\boldsymbol{\delta}$ masing-masing dinyatakan dengan $\widehat{\boldsymbol{\mu}}=\mathbf{X} \hat{\mathbf{a}} \operatorname{dan} \widehat{\boldsymbol{\delta}}=\widehat{\boldsymbol{\mu}} \hat{b}+\mathbf{1} \hat{d}$.

Proposisi 2.3.1. Hubungan berikut benar

$$
(\mathbf{m}-\widehat{\boldsymbol{\mu}})^{\prime} \widehat{\boldsymbol{\mu}}=0
$$

yaitu residual $(\mathbf{m}-\widehat{\boldsymbol{\mu}})$ tidak berkorelasi dengan estimasi pusat $\widehat{\boldsymbol{\mu}}$.

Bukti: Berdasarkan turunan parsial $\Delta_{L L}^{2}$ terhadap â seperti yang term(lat2db)am (2.2.1) diperoleh

$$
\begin{aligned}
& \frac{\partial \Delta_{L L}^{2}}{\partial \hat{\mathbf{a}}}=\mathbf{0} \\
& \Leftrightarrow 3\left(-2 \mathbf{X}^{\prime} \mathbf{m}+2 \mathbf{X}^{\prime} \mathbf{X} \hat{\mathbf{a}}\right) \\
& +2 \lambda^{2}\left(-2 \mathbf{X}^{\prime} \mathbf{l} \hat{b}+2 \mathbf{X}^{\prime} \mathbf{X} \hat{\mathbf{a}} \hat{b}^{2}\right. \\
& \left.+2 \mathbf{X}^{\prime} \mathbf{1} \hat{b} \hat{d}\right)=\mathbf{0} \\
& \Leftrightarrow \mathbf{X}^{\prime}\left(3(\mathbf{m}-\widehat{\boldsymbol{\mu}})+2 \lambda^{2} \hat{b}(\mathbf{l}-\mathbf{X} \hat{\mathbf{a}} \hat{b}-\mathbf{1} \hat{d})\right) \\
& =\mathbf{0}_{k+1} \\
& \Leftrightarrow \mathbf{X}^{\prime}\left(3(\mathbf{m}-\widehat{\boldsymbol{\mu}})+2 \lambda^{2} \hat{b}(\mathbf{l}-\widehat{\boldsymbol{\delta}})\right)=\mathbf{0}_{k+1} \text {. }
\end{aligned}
$$

Selanjutnya persamaan (2.3.2) di atas dapat ditulis

$$
\begin{aligned}
& \hat{\mathbf{a}}^{\prime} \mathbf{X}^{\prime}\left(3(\mathbf{m}-\widehat{\boldsymbol{\mu}})+2 \lambda^{2} \hat{b}(\mathbf{l}-\widehat{\boldsymbol{\delta}})\right)=\hat{\mathbf{a}}^{\prime} \mathbf{0}_{\boldsymbol{k}+\mathbf{1}} \\
& \Leftrightarrow \widehat{\boldsymbol{\mu}}^{\prime}\left(3(\mathbf{m}-\widehat{\boldsymbol{\mu}})+2 \lambda^{2} \hat{b}(\mathbf{l}-\widehat{\boldsymbol{\delta}})\right)=0 .
\end{aligned}
$$

Berdasarkan turunan parsial $\Delta_{L L}^{2}$ terhadap $\hat{b}$ yang termuat dalam (2.2.2) diperoleh 


$$
\begin{aligned}
& \frac{\partial \Delta_{L L}^{2}}{\partial \hat{b}}=0 \\
\Leftrightarrow & 2 \lambda^{2}\left(-2 \mathbf{l}^{\prime} \mathbf{X} \hat{\mathbf{a}}+2 \hat{\mathbf{a}}^{\prime} \mathbf{X}^{\prime} \mathbf{X} \hat{\mathbf{a}} \hat{b}+2 \mathbf{1}^{\prime} \mathbf{X} \hat{\mathbf{a}} \hat{d}\right)=0 \\
\Leftrightarrow & \hat{\mathbf{a}}^{\prime} \mathbf{X}^{\prime} \mathbf{X} \hat{\mathbf{a}} \hat{b}=\hat{\mathbf{a}}^{\prime} \mathbf{X}^{\prime} \mathbf{l}-\hat{\mathbf{a}}^{\prime} \mathbf{X}^{\prime} \mathbf{1} \hat{d} \\
\Leftrightarrow & \widehat{\boldsymbol{\mu}}^{\prime}(\mathbf{l}-\widehat{\boldsymbol{\delta}})=0 .
\end{aligned}
$$

Dengan mensubstitusi (2.3.4) ke (2.3.3), diperoleh

$$
\begin{aligned}
& \widehat{\boldsymbol{\mu}}^{\prime}(3(\mathbf{m}-\widehat{\boldsymbol{\mu}}))=0 \Leftrightarrow \widehat{\boldsymbol{\mu}}^{\prime}(\mathbf{m}-\widehat{\boldsymbol{\mu}})=0 \Leftrightarrow \\
& (\mathbf{m}-\widehat{\boldsymbol{\mu}})^{\prime} \widehat{\boldsymbol{\mu}}=0 . \mathbf{}
\end{aligned}
$$

Proposisi 2.3.2. Jumlahan (dan juga mean) dari $n$ residual pusat $(\mathbf{m}-\widehat{\boldsymbol{\mu}})$ dan jumlahan (dan juga mean) dari $n$ residual tepi $(\mathbf{l}-\widehat{\boldsymbol{\delta}})$ adalah nol, yaitu

$$
\begin{gathered}
\mathbf{1}^{\prime}(\mathbf{m}-\widehat{\boldsymbol{\mu}})=0 \\
\mathbf{1}^{\prime}(\mathbf{l}-\widehat{\boldsymbol{\delta}})=0
\end{gathered}
$$

Bukti:

(i). Akan ditunjukkan benar untuk persamaan (2.3.6). Berdasarkan turunan parsial $\Delta_{L L}^{2}$ terhadap $\hat{d}$ yang termuat dalam (2.2.3), diperoleh

$$
\begin{aligned}
\frac{\partial \Delta_{L L}^{2}}{\partial \hat{d}}=0 & \Leftrightarrow-\mathbf{1}^{\prime} \mathbf{1}+\mathbf{1}^{\prime} \mathbf{X} \hat{\mathbf{a}} \hat{b}+n \hat{d}=0 \\
& \Leftrightarrow \mathbf{1}^{\prime} \mathbf{1}-\mathbf{1}^{\prime} \widehat{\boldsymbol{\mu}} \hat{b}-\mathbf{1}^{\prime} \mathbf{1} \hat{d}=0 \\
& \Leftrightarrow \mathbf{1}^{\prime}(\mathbf{l}-\widehat{\boldsymbol{\delta}})=0 .
\end{aligned}
$$

(ii). Berdasarkan basis jarak pada persamaan (2.1), dapat dituliskan

$$
\begin{aligned}
\Delta_{L L}^{2} & =\left\|\begin{array}{l}
3(\mathbf{m}-\widehat{\boldsymbol{\mu}}) \\
2 \lambda^{2}(\mathbf{l}-\widehat{\boldsymbol{\delta}})
\end{array}\right\|^{2} \\
& =\left\|\begin{array}{c}
3(\mathbf{m}-\mathbf{X} \hat{\mathbf{a}}) \\
2 \lambda^{2}(\mathbf{l}-\mathbf{X} \hat{\mathbf{a}} \hat{b}-\mathbf{1} \hat{d})
\end{array}\right\|^{2} \\
& =\|\left(\begin{array}{c}
3 \mathbf{m} \\
2 \lambda^{2}(\mathbf{l}-\mathbf{1} \hat{d})
\end{array}\right)-
\end{aligned}
$$$$
3 \mathbf{X} 2 \lambda 2 \mathbf{X} b \mathbf{a} 2=\mathbf{y}-\mathbf{Z a} 2 .
$$

Dalam hal ini, regresi fuzzy dengan variabel dependen fuzzy ditransformasi ke dalam masalah regresi biasa antara $\mathbf{y}$ (vektor variabel dependen) dan $\mathbf{Z}$ (matriks variabel independen). Selanjutnya berdasarkan sifat estimasi regresi biasa, diketahui bahwa untuk vektor optimal â diperoleh

$$
1^{\prime} \mathbf{y}=1^{\prime} \mathbf{Z a ̂} \text {. }
$$

Dengan mensubstitusi $\mathbf{y}$ dan $\mathbf{Z}$ dalam (2.3.7) ke dalam (2.3.8), diperoleh

$$
\begin{gathered}
\mathbf{1}^{\prime} 3 \mathbf{m}+\mathbf{1}^{\prime} 2 \lambda^{2} \mathbf{l}-\mathbf{1}^{\prime} 2 \lambda^{2} \mathbf{1} \hat{d} \\
=\mathbf{1}^{\prime} 3 \mathbf{X} \hat{\mathbf{a}}+\mathbf{1}^{\prime} 2 \lambda^{2} \mathbf{X} \hat{\mathbf{a}} \hat{b} \\
\Leftrightarrow 0=\mathbf{1}^{\prime} 3 \mathbf{m}+\mathbf{1}^{\prime} 2 \lambda^{2} \mathbf{l}-\mathbf{1}^{\prime} 2 \lambda^{2} \mathbf{1} \hat{d}- \\
\mathbf{1}^{\prime} 3 \mathbf{X} \hat{\mathbf{a}}-\mathbf{1}^{\prime} 2 \lambda^{2} \mathbf{X} \hat{\mathbf{a}} \hat{b} \\
\Leftrightarrow 3\left[\mathbf{1}^{\prime}(\mathbf{m}-\widehat{\boldsymbol{\mu}})\right]=-2 \lambda^{2}\left[\mathbf{1}^{\prime}(\mathbf{l}-\widehat{\boldsymbol{\delta}})\right] .
\end{gathered}
$$

Dengan mensubstitusi (2.3.6) ke dalam (2.3.9), diperoleh

$$
3\left[\mathbf{1}^{\prime}(\mathbf{m}-\widehat{\boldsymbol{\mu}})\right]=0 \Leftrightarrow \mathbf{1}^{\prime}(\mathbf{m}-\widehat{\boldsymbol{\mu}})=0 .
$$

Proposisi 3.3. Hubungan berikut benar

$$
(\mathbf{l}-\widehat{\boldsymbol{\delta}})^{\prime} \widehat{\boldsymbol{\delta}}=0 .
$$

yaitu residual $(\mathbf{l}-\widehat{\boldsymbol{\delta}})$ tidak berkorelasi dengan estimasi tepi $\widehat{\boldsymbol{\delta}}$.

Bukti: Berdasarkan (2.3.4) diperoleh

$$
\begin{gathered}
\widehat{\boldsymbol{\mu}}^{\prime}(\mathbf{l}-\widehat{\boldsymbol{\delta}})=0 \\
\Leftrightarrow(\mathbf{l}-\widehat{\boldsymbol{\delta}})^{\prime} \mathbf{X} \hat{\mathbf{a}}=0 \\
\Leftrightarrow(\mathbf{l}-\widehat{\boldsymbol{\delta}})^{\prime} \text { Xââ }=0 .
\end{gathered}
$$

Selanjutnya dalam proposisi 2.3 .2 , persamaan (2.3.6) ditunjukkan

$$
\begin{gathered}
\mathbf{1}^{\prime}(\mathbf{l}-\widehat{\boldsymbol{\delta}})=0 \\
\Leftrightarrow(\mathbf{l}-\widehat{\boldsymbol{\delta}})^{\prime} \mathbf{1} \hat{d}=0 .
\end{gathered}
$$

Dengan demikian berdasarkan (2.3.11) dan (2.3.12) diperoleh 


$$
\begin{gathered}
(\mathbf{l}-\widehat{\boldsymbol{\delta}})^{\prime} \mathbf{X} \hat{\mathbf{a}} \hat{b}+(\mathbf{l}-\widehat{\boldsymbol{\delta}})^{\prime} \mathbf{1} \hat{d}=0 \\
\Leftrightarrow(\mathbf{l}-\widehat{\boldsymbol{\delta}})^{\prime}(\mathbf{X} \hat{\mathbf{a}} \hat{b}+\mathbf{1} \hat{d})=0 \\
\Leftrightarrow(\mathbf{l}-\widehat{\boldsymbol{\delta}})^{\prime} \widehat{\boldsymbol{\delta}}=0 .
\end{gathered}
$$

\section{SIMPULAN}

Berdasarkan uraian di atas, dapat ditarik beberapa simpulan antara lain: (i) model regresi fuzzy dengan variabel dependen fuzzy simetris merupakan perluasan model regresi klasik dengan menambahkan model regresi linear sederhana untuk model tepi, (ii) kriteria kuadrat terkecil diadopsi untuk mengestimasi parameter dari model dengan meminimalkan kuadrat jarak fuzzy antara variabel dependen terobservasi $\tilde{Y}$ dengan nilai teoritis yang berkorespondensi $\tilde{Y}^{*}$, (iii) solusi iteratif dari model yang didapat dengan menentukan turunan parsial fungsi jarak terhadap parameter yang diestimasi merupakan generalisasi solusi regresi klasik, dan (iv) dibuktikan beberapa sifat solusi iteratif dari model. Selanjutnya masih diperlukan penyelidikan lebih lanjut berkaitan dengan sifat-sifat solusi model, serta pengembangan dan aplikasi model regresi fuzzy ini dalam permasalahan kehidupan sehari-hari.

\section{DAFTAR PUSTAKA}

Celmins, A. 1987. Multidimensional leastsquares fitting of fuzzy models, Math. Model. 9, 669-690.

Chang, P.T. and E. S. Lee. 1996. A generalized fuzzy weighted least-squares regression, Fuzzy Sets and Systems 82, 289-298.

Chang, Y.-H. O. and B. M. Ayyub. 2001. Fuzzy regression methods-a comparative assessment, Fuzzy Sets and Systems 119, 187-203.

Chen, G. and T. T. Pham. 2001. Introduction to fuzzy sets, fuzzy logic, and fuzzy control systems, Boca Raton: CRC Press.

Coppi, R. 2008. Management of uncertainty in statistical reasoning: The case of regression analysis, International Journal of Approximate Reasoning 47, 284-305.

Coppi, R. and P. D'Urso. 2003. Regression analysis with fuzzy informational paradigm: a least squares approach using membership function information, Int. J. Pure Appl. Math. 8, no. 3, 279-306.

Coppi, R., P. D'Urso, P. Giordani, and A. Santoro. 2006. Least squares estimation of a linear regression model with LR fuzzy response, Computational Statistics \& Data Analysis 51, 267-286.

Coppi, R., M. A. Gil, and H. A. L. Kiers. 2006. The fuzzy approach to statistical analysis, Computational Statistics \& Data Analysis 51, 1-14.

Coppi, R., P. Giordani, and P. D'Urso. 2006. Component models for fuzzy data, Psychometrika 71, no. 4, 733-761.

Diamond, P. 1998. Fuzzy least squares, Information Sciences 46, 141-157.

D'Urso, P. 2003. Linear regression analysis for fuzzy/crisp input and fuzzy/crisp output data, Computational Statistics \& Data Analysis 42, 47-72.

D'Urso, P. and T. Gastaldi. 2000. A leastsquares approach to fuzzy linear regression analysis, Computational Statistics \& Data Analysis 34, 427-440.

------. 2002. An "orderwise" polynomial regression procedure for fuzzy data, Fuzzy Sets and Systems 130, 1-19.

D'Urso, P. and P. Giordani. 2003. Fitting of fuzzy linear regression models with multivariate response, Int. Math. J. 3, no. 6, 655-664.

------. 2006. A weighted fuzzy c-means clustering model for fuzzy data, 
Computational Statistics \& Data Analysis 50, no. 6, 1496-1523.

D'Urso, P. and A. Santoro. 2006a. Fuzzy clusterwise linear regression analysis with symmetrical fuzzy output variable, Computational Statistics \& Data Analysis 51, 287-313.

2006b. Goodness of fit and variable selection in the fuzzy multiple linear regression, Fuzzy Sets and Systems 157, 2627-2647.

Giachetti, R. E. and R. E. Young. 1997. A parametric representation of fuzzy numbers and their arithmetic operators, Fuzzy Sets and Systems 91, 185-202.

Kharisudin, I. and Subanar. 2009. Fuzzy regression analysis with symmetrical fuzzy dependent variable, The Proceeding of IICMA 2009, ISBN: 978-602-96426-0-5, pp 935-950.

Ma, M., M. Friedman, and A. Kandel. 1997. General fuzzy least squares, Fuzzy Sets and Systems 88, 107-118.

Shapiro, A. F. 2005. Fuzzy regression and the term structure of interest rates revisited, Unpublished paper, Penn State University.

Taheri, S. M. 2008. C-fuzzy numbers and a dual of extension principle, Information Sciences 178, 827-835.

Tanaka, H., S. Uejima, and K. Asai. 1982. Linear regression analysis with fuzzy model, IEEE Transactions on Systems, Man and Cybernetics 12, no. 6, 903-907.

Wu, H. C. 2003. Fuzzy least squares estimators in linear regression analysis for imprecise input and output data, Computational Statistics \& Data Analysis 42, 203-217.

Yang, M.-S. and C.-H. Ko. 1996. On a class of fuzzy c-numbers clustering procedures for fuzzy data, Fuzzy Sets and Systems 84, 4960.

Zadeh, L. A. 1999. Fuzzy sets as a basis for a theory of possibility, Fuzzy Sets and Systems 100 Supplement, 9-34.
Zimmermann, H. J. 1991. Fuzzy set theory and its applications, Boston: Kluwer Academic Publisher. 